\title{
EFEITOS DA PANDEMIA DA COVID-19 NAS MIGRAÇÕES INTERNACIONAIS PARA O MERCOSUL E A UNIÃO EUROPEIA: ASPECTOS NORMATIVOS E CENÁRIOS POLÍTICOS
}

Eveline Vieira Brígido

Roberto Rodolfo Georg Uebel²

\begin{abstract}
SINOPSE
A pandemia de Covid-19 provocou grandes impactos e transformações no Sistema Internacional (SI), demandando que Estados e blocos regionais desempenhassem novas ações diante de seus efeitos sanitários, políticos e econômicos. Estima-se que 70 milhões de migrantes sejam impactados pela pandemia, cujos reflexos observam-se sobretudo no mercado de trabalho, no acesso à saúde pública e no controle fronteiriço. Este texto tem como objetivo, portanto, analisar os efeitos da pandemia da Covid-19 nas migrações internacionais para o Mercado Comum do Sul (Mercosul) e para a União Europeia, em uma perspectiva comparada, bem como identificar os aspectos jurídicos e institucionais e políticos e econômicos neste cenário. Por fim, o texto promove a discussão, de maneira arrazoada, sobre as respostas dos dois blocos e aponta as perspectivas para o cenário migratório em ambas as regiões no pós-pandemia.
\end{abstract}

Palavras-chave: pandemia; Covid-19; migrações; Mercosul; União Europeia.

\begin{abstract}
The Covid-19 pandemic caused great impacts and shifts in the international system, demanding that States and regional blocs take new actions considering its sanitary, political, and economic effects. It is estimated that 70 million migrants would be impacted by the pandemic, which reflects mainly on the labour market, access to public health and border control. Thus, this article analyses the effects of the Covid-19 pandemic on international migrations to Mercosul and the European Union, in a comparative perspective, and it identifies the legal and institutional and the political and economic aspects in this scenario. Finally, the article promotes a brief discussion on the responses of the two blocs and points out the prospects for the migration scenario in both regions in the post-pandemic.
\end{abstract}

Keywords: pandemic; Covid-19; migrations; Mercosul; European Union.

JEL: F22.

Artigo recebido em 23/7/2020 e aprovado em 6/8/2020.

DOI: http://dx.doi.org/10.38116/bepi27art3

\section{INTRODUÇÃO}

A comunidade internacional enfrenta atualmente a pior crise migratória desde a Segunda Guerra Mundial. Milhóes de pessoas têm abandonado suas residências a fim de buscar proteção em outras cidades ou em outros países. Ao final de 2019, contabilizavam-se 30,2 milhôes de refugiados e

\footnotetext{
1. Doutora em ciência política pela Universidade Federal do Rio Grande do Sul (UFRGS); professora de relações internacionais na Escola Superior de Propaganda e Marketing (ESPM); e pesquisadora do grupo de pesquisa Novos Polos de Poder e a Política Internacional na ESPM. E-mail: <ebrigido@espm.br>.

2. Doutor em estudos estratégicos internacionais pela UFRGS; professor de relações internacionais na ESPM; e pesquisador do grupo de pesquisa Novos Polos de Poder e a Política Internacional na ESPM. E-mail: <roberto.uebel@espm.br>.
} 
solicitantes de refúgio, de acordo com o Alto Comissariado das Naçóes Unidas para os Refugiados (ACNUR). ${ }^{3}$ Se fossem contabilizados migrantes forçados internos (deslocados internos), esse número passaria para 79,5 milhôes. Essa quantidade, no entanto, é muito mais elevada. Primeiro, porque nem todos os migrantes forçados se enquadram nos requisitos legais para a solicitação de refúgio. Segundo, porque mesmo os que se enquadrariam às vezes continuam irregulares por receio de serem deportados, uma vez que não sabem se têm direito a asilo.

A América do Sul e a Europa são dois continentes fortemente atingidos pela crise, o que impacta o andamento de blocos regionais nessas respectivas regiốes. Em relação a esses blocos, destacam-se o Mercado Comum do Sul (Mercosul) e a União Europeia, que preveem em suas legislaçóes internas a livre circulaçáo de seus nacionais e residentes. Ou seja, se um grande fluxo de migrantes originários de terceiros países entrar nesses blocos, gerará um impacto no sistema da livre circulação de nacionais. Como exemplo temos o fechamento de algumas fronteiras dentro do Espaço Schengen ${ }^{4}$ em 2015, no auge da crise migratória europeia, e o controle de migrantes oriundos da Venezuela - um Estado-membro do Mercosul $^{5}$-, também a partir de 2015, pelos demais membros do bloco, em virtude da crise econômica e política que afeta aquele país.

Dessa maneira, se já é difícil administrar a crise migratória em "tempos normais", essa tarefa torna-se ainda mais complexa durante uma pandemia, declarada pela Organizaçáo Mundial da Saúde (OMS) em 11 de março de 2020.

A Covid-19 atingiu os cinco continentes, de forma que diversos países estáo enfrentando graves crises sanitárias, além de econômicas e políticas. Se o novo vírus já um problema para as pessoas que vivem normalmente em suas residências habituais, torna-se ainda mais grave para os migrantes, em especial os forçados. São pessoas muitas vezes sem acompanhamento da família, sem emprego (ou com trabalho informal) e sem reservas financeiras. É importante salientar que esses migrantes costumam ser dependentes de redes de solidariedade, como organizaçóes não governamentais (ONGs), igrejas, associaçóes de migrantes etc., que ficaram sobrecarregadas com os impactos econômicos e sociais da pandemia sobre os nacionais, inclusive com abrigos sociais fechados, conforme relataremos nas próximas seçôes.

Os países estão administrando maneiras de amenizar a crise em duas frentes: a sanitária e a econômica. E, além das medidas tomadas em âmbito doméstico, existem também aquelas tomadas pelas instituições dos blocos regionais. É possível dizer que se trata de regulamentaçôes sob um aspecto mais amplo, ao passo que os governos nacionais tomam decisóes para questóes mais específicas, focadas em problemas internos. De qualquer forma, essas decisóes nacionais devem estar em conformidade com as orientaçôes determinadas pelas organizações regionais.

Sendo assim, este texto tem como objetivo analisar e comparar as regulamentaçóes relacionadas às migraçôes e à Covid-19 no âmbito do Mercosul e da União Europeia. A fim de cumprir esse objetivo, será realizado, na seção 2 , um retrospecto sobre a questão das migraçôes e da pandemia.

3. Disponível em: <https://www.unhcr.org/data.html>. Acesso em: 19 jul. 2020.

4. 0 Espaço Schengen envolve também países que não são membros da União Europeia: Islândia, Liechtenstein, Noruega e Suíça. Em contrapartida, não engloba alguns Estados-membros do bloco: Irlanda, Bulgária, Romênia, Chipre e Croácia.

5. A República Bolivariana da Venezuela se encontra suspensa de todos os direitos e obrigações inerentes à sua condição de Estado-parte do Mercosul desde agosto de 2017, em conformidade com o disposto no art. 5o do Protocolo de Ushuaia. Disponível em: <https://www. mercosur.int/pt-br/decisao-sobre-a-suspensao-da-republica-bolivariana-da-venezuela-no-mercosul/>. Acesso em: 13 jul. 2020. 
Nas seçôes 3 e 4, serão estudados os aspectos jurídicos, institucionais, políticos e econômicos da União Europeia e do Mercosul, respectivamente. Ao final, na seção de considerações finais, será feita uma comparação sobre as regulamentaçóes de ambos os blocos e o apontamento de perspectivas para o cenário migratório em ambas as regióes no período pós-pandemia.

Esta é uma pesquisa qualitativa e exploratória, na qual se utilizam fontes bibliográficas e documentais, conforme Gil (2019). Será dada ênfase, em especial, às normativas do Mercosul e da União Europeia - para tanto, nas seçôes 3 e 4, dividiremos as análises em subgrupos, abordando os aspectos jurídicos e institucionais e os aspectos políticos e econômicos.

Espera-se, portanto, com este trabalho, buscar uma reflexão acerca dos efeitos da pandemia da Covid-19 - que poderá impactar 79,5 milhóes de migrantes, de acordo com a ONG Refugees International ${ }^{6}$ - nas migraçóes internacionais, especialmente nos dois blocos mencionados, bem como promover a discussão, de maneira arrazoada, sobre as respostas normativas, políticas e institucionais do Mercosul e da União Europeia diante da pandemia e dos seus próprios cenários migratórios.

\section{MIGRAÇÕES E PANDEMIA}

Atualmente, a sociedade internacional enfrenta uma séria crise migratória, especialmente em virtude de diversos conflitos, ou seja, uma situação de migração forçada, na qual as pessoas são obrigadas a abandonar suas residências. A atual crise migratória europeia teve início entre 2011 e 2012, especialmente em razão da guerra na Síria. Trata-se de um conflito que gerou fuga em massa de sírios, iniciou-se com a Primavera Árabe em 2011 e agravou-se com o surgimento do Estado Islâmico. Desde 2015, a Síria é o país com o maior número de refugiados e deslocados internos.

O conflito sírio, todavia, veio a somar-se com conflitos em outros países onde já existiam grandes fluxos de refugiados e deslocados internos, com destaque para o Afeganistão e o Iraque. Além disso, devem-se ressaltar os diversos conflitos em países africanos, destacando-se República Centro-Africana, República Democrática do Congo, Sudão, Sudão do Sul, Mali e Somália. E, a partir de 2016, Mianmar e Venezuela também passaram a fazer parte dos países com grave crise migratória. Não obstante, os venezuelanos náo estão nos dados oficiais do ACNUR, uma vez que parte deles foi recebida nos países da regiáo por meio de alternativas legais, permitidas pelos sistemas jurídicos. De qualquer forma, o ACNUR estima que havia cerca de 3,6 milhões de migrantes forçados venezuelanos em 2019. A fim de melhor visualizar a crise migratória, ver o gráfico 1 , que não inclui os venezuelanos.

Como se pode perceber, a crise foi aumentando no decorrer dos anos e ocorre principalmente no âmbito interno dos Estados. Apesar disso, essas crises migratórias internas, na maioria dos casos, acabam se transformando em internacionais. Isto é, os deslocados internos, muitas vezes, acabam por deixar seus países para buscar refúgio em outros. A partir desse momento, tornam-se solicitantes de refúgio e, uma vez que este tenha sido reconhecido, eles viram refugiados. Todos, independentemente da denominação (deslocado interno, solicitante de refúgio ou refugiado), estáo em situação de vulnerabilidade.

6. Disponível em: <https://bit.ly/3jwdCB1>. Acesso em: 13 jul. 2020. 
GRÁFICO 1

Atual crise migratória mundial (2011-2019)

(Em milhões)

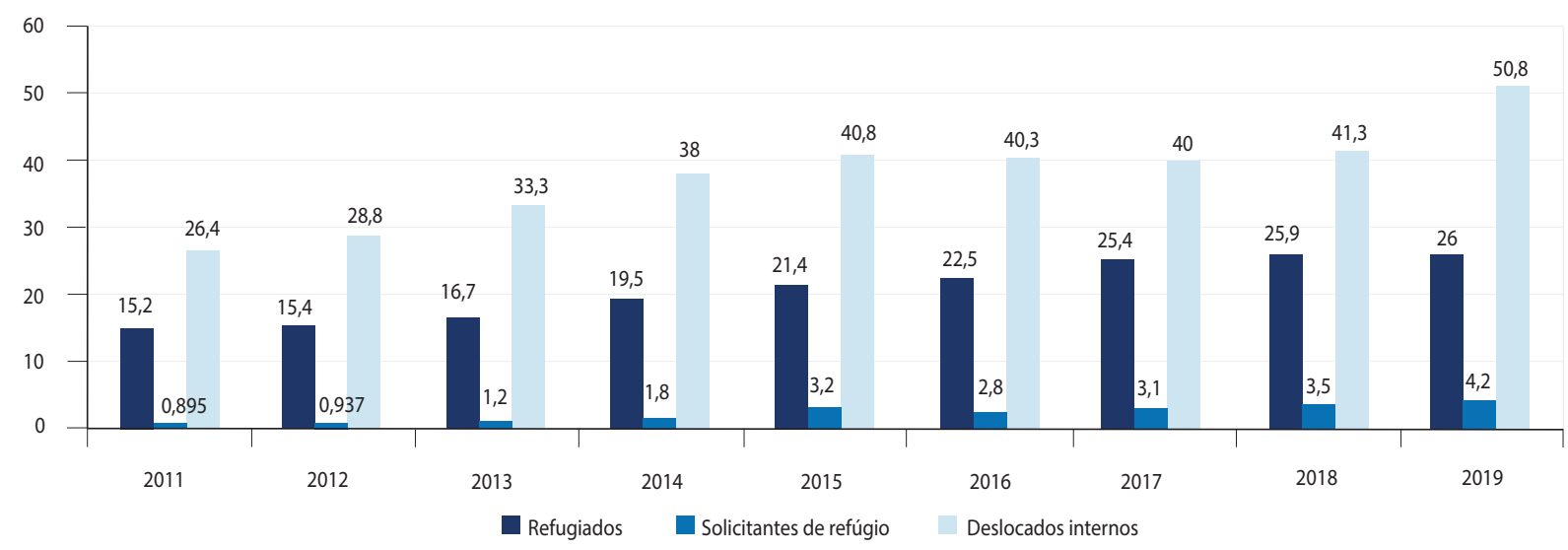

Fonte: ACNUR, 2020; Centro de Monitoramento dos Deslocados Internos, 2020.

Elaboração dos autores.

O ACNUR destaca os seguintes países com o maior fluxo de migrantes internacionais forçados em 2019: Burundi, República Democrática do Congo, Mianmar, Síria, Iêmen, República Centro-Africana, Nigéria, Sudáo do Sul e Venezuela. E, se considerarmos o grande aumento de deslocados internos em 2019, é possível prever que vai haver um forte aumento de refugiados na sequência, haja vista a situação de crise criada pela pandemia da Covid-19 desde meados de 2020.

Outro aspecto importante a ser mencionado é o das migraçóes voluntárias - ou econômicas (Massey, 2017), ou de perspectiva (UEBEL, 2018) -, que também passaram por um aumento considerável ao longo das últimas duas décadas em virtude dos shifts impostos pelas mudanças no Sistema Internacional (SI) e nas próprias relaçóes laborais e econômicas do meio técnico-científico-informacional (Santos, 2006), ou seja, no mundo onde as relaçôes técnicas (sobretudo políticas), científicas e da informação impactam cada vez mais o SI.

Entre essas transformaçóes, os efeitos da pandemia da Covid-19, declarada em março de 2020, após o surto inicial na China, que rapidamente teve epicentros posteriores na Itália, na Espanha, nos Estados Unidos e, mais recentemente, no Brasil, são intensificados em uma conjuntura que implica uma maior vulnerabilização dos migrantes voluntários e forçados, haja vista o fechamento de fronteiras, a proibição de viagens, a interrupçáo de voos e transportes rodoviários e o aumento do controle da mobilidade humana. Tudo isso para evitar a propagação do novo coronavírus, causador da doença pandêmica.

Para se ter uma dimensão da pandemia, a partir dos dados nacionais compilados pela Universidade Johns Hopkins, em 4 de agosto, registravam-se 18,31 milhões de casos confirmados de Covid-19 e 694.713 óbitos em todo o mundo. A tabela 1 a seguir elenca os trinta países com o maior número de casos e óbitos pela doença, respectivamente. 


\section{TABELA 1}

Número de casos confirmados e óbitos por Covid-19 nos trinta países com maior incidência (4 ago./2020)

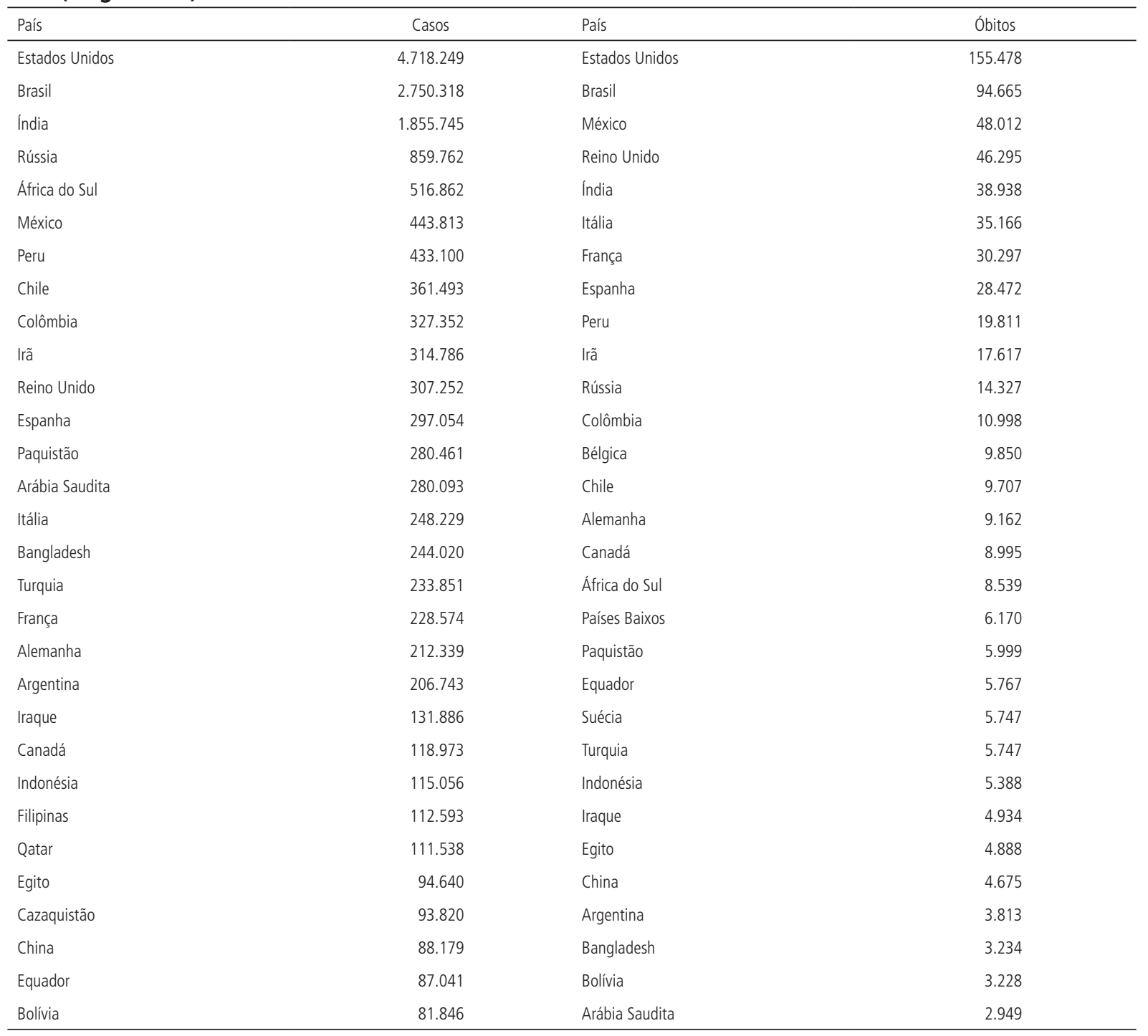

Fonte: Universidade Johns Hopkins. Disponível em: <https://coronavirus.jhu.edu/map.html>. Acesso em: 4 ago. 2020.

Elaboração dos autores.

Europa e América do Sul, além de Estados Unidos e México, despontam como as regiôes com maior incidência de óbitos e contaminados pela Covid-19. A geografia da pandemia permite observar, conforme a figura 1, que a incidência nas bordas dos blocos europeu e mercosulino resultou em desafios maiores para os fluxos migratórios já consolidados para as duas regióes, sobretudo aqueles oriundos do Norte da África e do Oriente Médio para o Leste Europeu e a Europa Central, e de venezuelanos e caribenhos (haitianos em maior grau) para os países do Mercosul, notadamente Brasil e Argentina. 


\section{FIGURA 1}

\section{Cenário global da pandemia da Covid-19 (4 ago./2020)}

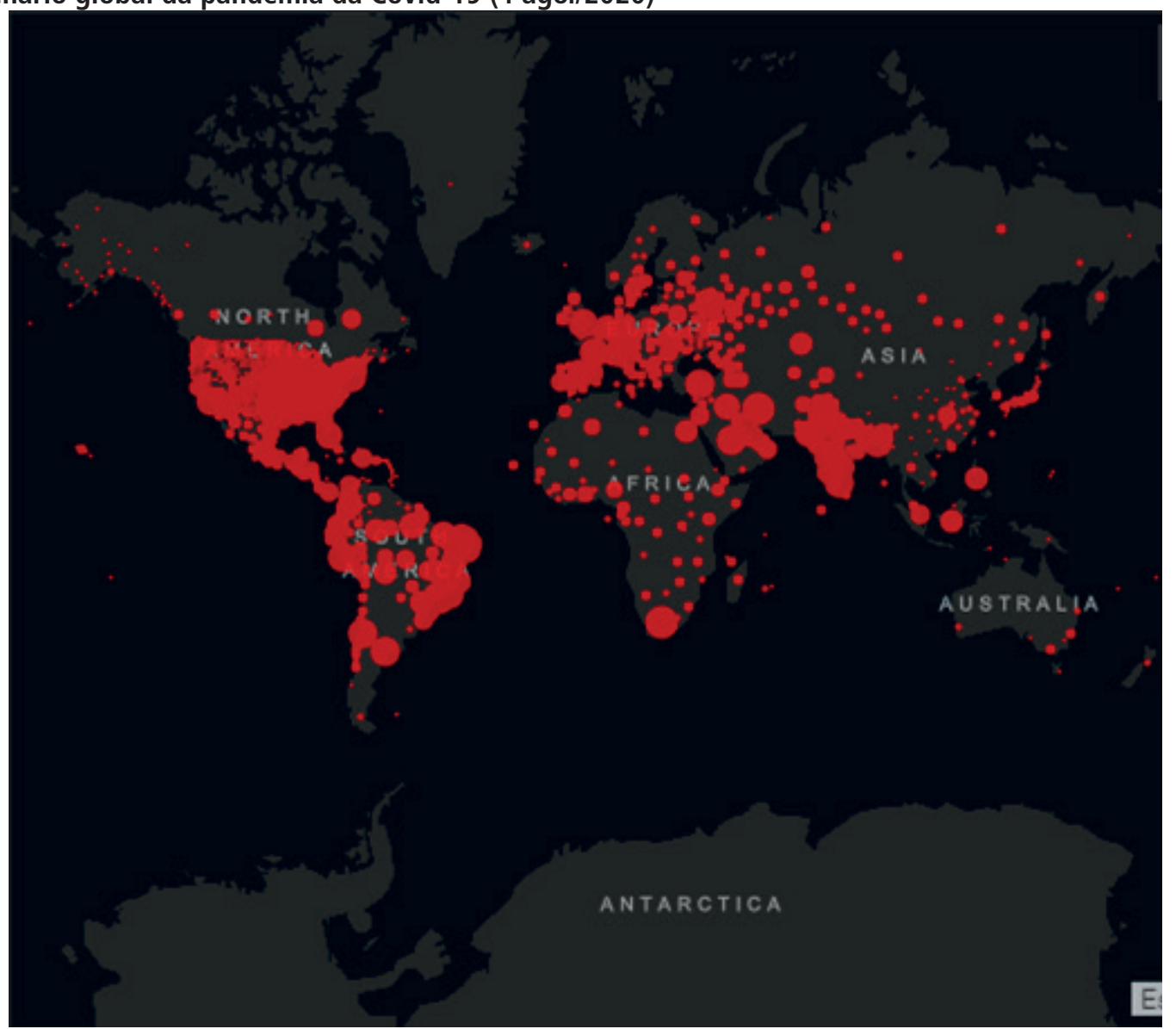

Fonte: Universidade Johns Hopkins. Disponível em: <https://coronavirus.jhu.edu/map.html>. Acesso em: 4 ago. 2020.

Obs.: Figura cujos leiaute e textos não puderam ser padronizados e revisados em virtude das condições técnicas do original (nota do Editorial)

Nesse sentido, a pandemia implicou um agravamento dos tensionamentos fronteiriços em ambas as regióes, em razáo do aumento e da concentraçáo de migrantes nos postos de controle, entáo fechados ou com o acesso restrito. No caso de Melilla, território espanhol e, portanto, europeu, no continente africano, o cenário agravado pela Covid-19 foi conforme descrito a seguir.

Um guarda de fronteira sofreu ferimentos leves. Os relatórios são do chefe da força policial da Guarda Civil, José Manuel Santiago, que observou que "260 migrantes tentaram escalar" o muro de metal na fronteira, mas que "apenas 53 conseguiram atravessar". "Continuaremos a trabalhar com o Marrocos para evitar esse tipo de situação, não vamos baixar a guarda”, disse Santiago quando perguntado se o bloqueio afetou a segurança nas fronteiras. A Espanha convocou uma grande parte de suas forças de segurança para reforçar a proibição de circulação como parte dos esforços para impedir a propagação da Covid-19. Cerca de 13 mil pessoas na Espanha que testaram positivo para o vírus morreram. "Eles usaram ganchos de metal na sua tentativa e jogaram pedras na polícia”, disse ele em entrevista coletiva (Melilla, 2020, tradução nossa).?

7. "One border guard sustained minor injuries. Reports were from Guardia Civil police force chief Jose Manuel Santiago, who noted that '260 migrants tried to climb over' the metal fence on the border but that 'only 53 managed to cross' over. 'We will continue to work with Morocco to avoid this type of situation, we will not let down our guard, 'Santiago said when asked if the lockdown had affected border security. Spain has called up a large part of its security forces to enforce a ban on movement as part of efforts to halt the spread of Covid-19. Some 13,000 people in Spain who tested positive for the virus have died. 'They used metal hooks in their attempt and threw rocks at police,' he told a news conference". 
Já no âmbito do Mercosul, o caso mais emblemático - e também com os maiores efeitos sobre migrantes, conforme veremos nas próximas seçôes - foi o fechamento dual da fronteira Brasil-Venezuela, ordenado tanto por Brasília como por Caracas, a fim de conter a propagaçáo do novo coronavírus (Paduan, 2020; Maduro, 2020).

Outro aspecto a ser considerado no âmbito das migrações em um contexto de pandemia é como a mobilidade humana sofre imediatamente os impactos nos mais diversos campos, desde o fechamento das fronteiras, conforme apontado anteriormente, até o acesso aos serviços públicos de saúde; a interrupção das atividades laborais - ainda que irregulares, dada a restrição da circulação de pessoas - em virtude de medidas de distanciamento social, como o lockdown; a não concessão de auxílios financeiros por governos; e a própria remessa internacional de valores para seus familiares nos países de origem, com o fechamento de bancos, agências postais e despachantes. De fato, migrantes são os primeiros a sofrer os maiores efeitos de uma pandemia.

A anomia social causada por uma pandemia representa também impactos psicológicos consideráveis, conforme já apontado por Choudhari (2020) e Rothman, Gunturu e Korenis (2020), no contexto pandêmico atual, o que nos leva a prospectar tais efeitos também para migrantes, sobretudo aqueles em maior situação de vulnerabilidade, como refugiados e solicitantes de refúgio.

Pode-se vislumbrar a ocorrência de um choque negativo de expectativas nesses grupos, uma vez que estes almejavam uma possibilidade de melhorar de vida, o que foi subitamente afetado pelos efeitos da pandemia sobre o emprego, por exemplo. Os primeiros estudos, como o descrito por Mantovani (2020), já demonstram a piora da vulnerabilidade social entre migrantes venezuelanos no Brasil.

\begin{abstract}
Mais de $80 \%$ disseram que essa renda piorou durante a pandemia, assim como o acesso à comida - o que é ainda mais grave porque, na infância, a desnutrição pode deixar marcas duradouras. A maioria afirmou que a família toda está em casa durante a quarentena, mas 40,8\% disseram que alguém sai para trabalhar fora. No Brasil, o número ultrapassa os $60 \%$. Mais de $60 \%$ tiveram que parar de ir à escola neste período, $34 \%$ disseram não ter acesso a serviços de saúde e $20 \%$, nem água e sabão para se precaver contra o coronavírus. Pouco mais de $30 \%$ disseram que a pandemia gera algum tipo de discriminaçáo, especialmente em relação aos venezuelanos. A situação da moradia também se mostrou precária: $28 \%$ das crianças entrevistadas estão em risco de serem desalojadas por falta de pagamento do aluguel, 6,9\% foram de fato despejadas e $10 \%$ tiveram que ir para um abrigo.
\end{abstract}

Nessa dimensão, veremos nas próximas seçôes como a União Europeia e o Mercosul, que apresentam cenários semelhantes (de maneira proporcional), têm respondido institucionalmente aos efeitos da pandemia nas migraçóes internacionais, considerando, sobretudo, os aspectos legais, institucionais, políticos e econômicos.

Assim como Sayad (1998) reflete que as migraçóes se dáo pelo trabalho, em que pesem as migraçôes forçadas causadas por guerras e perseguições políticas, sociais e religiosas, será justamente por meio da via laboral que a pandemia da Covid-19 tecerá os seus maiores impactos - e dramas em migrantes, seus familiares e seus projetos migratórios. Em contrapartida, blocos regionais em crises estruturais, como a União Europeia pós-Brexit e o Mercosul dividido entre as agendas de política externa de Brasília e Buenos Aires, também se emaranham nessas teias de impactos da maior pandemia desde a Gripe de 1918. 


\section{O CENÁRIO NA UNIÃO EUROPEIA}

\subsection{Aspectos jurídicos e institucionais}

A Europa foi o segundo continente fortemente atingido pela Covid-19, tendo a crise sanitária se agravado na Itália inicialmente e, logo após, se espalhado para países vizinhos. E a resposta não foi apenas dos governos locais e nacionais, mas em conjunto com as determinaçóes das instituiçóes europeias, que, desde o início, têm trabalhado vigorosamente para administrar a pandemia dentro do bloco europeu.

É importante ressaltar que a crise sanitária se somou à outra já estabelecida: a migratória. O continente europeu, em especial a região que engloba os países-membros da União Europeia, tem proximidade geográfica com países de onde se origina um grande fluxo de refugiados, sendo que a principal rota de migrantes é via Grécia. Desde o início da Primavera Árabe, o fluxo se intensificou, de forma que em 2015 alguns países do Espaço Schengen chegaram a fechar as fronteiras temporariamente.

Com relação à circulação de pessoas dentro do bloco, é preciso distinguir entre nacionais dos Estados-membros e de terceiros países. A União Europeia prevê a livre circulação de pessoas internamente, a partir da criação do Espaço Schengen. Com relação às migraçóes forçadas, foi criado o Sistema Comum de Asilo Europeu, tendo um conjunto de regulamentaçóes comunitárias para administrar os migrantes forçados: diretiva sobre o Estatuto dos Refugiados, diretiva sobre os procedimentos de asilo, diretiva sobre as condiçóes de acolhimento e os regulamentos de Dublin. Essas regras são internas e todos os Estados-membros devem adotá-las, podendo estabelecer condiçôes mais protetivas que as previstas em âmbito europeu.

A crise migratória, agravada pela Primavera Árabe a partir de 2011, fez com que os diversos regulamentos fossem revisados e também com que fosse firmado um tratado com a Turquia em 2016, para conter os migrantes, em especial sírios, em seu território. Tal acordo foi alvo de diversas críticas, uma vez que a Turquia náo é considerada um país que respeite os direitos humanos nos termos previstos pelas legislações europeias e internacionais, tendo sido visto apenas como um meio para diminuir o fluxo de imigrantes para a Europa em vez de resolver de fato a situação. A Human Rights Watch, ${ }^{8}$ por exemplo, assinalou que, no momento do acordo em 2016, já havia na Turquia mais de 2 milhões de refugiados sírios, e enviar ainda mais refugiados sírios só agravaria a situação, não havendo garantias de respeito aos direitos humanos básicos, como saúde e educação. Há também críticas em relação aos interesses turcos, como a facilitação para a entrada da Turquia na União Europeia, a isenção de vistos para cidadãos turcos no Espaço Schengen, a facilitação do acordo de união aduaneira com o bloco europeu, entre outras (Ruyt, 2015). Portanto, havia interesses estratégicos de ambos os lados.

No final de fevereiro de 2020, no entanto, houve uma forte crise entre a União Europeia e a Turquia, sob a alegaçáo turca de que os europeus não estavam cumprindo o prometido no acordo, com destaque para o pagamento de $€ 6$ bilhóes, montante que foi saldado apenas parcialmente. Em razão das novas discussôes, o acordo está sendo revisado (Uras, 2020).

Para piorar a situação, as divergências entre a Turquia e a União Europeia ocorreram justamente no momento em que a Itália e a Espanha enfrentavam um grande aumento diário de mortes e

8. Disponível em: <https://www.hrw.org/news/2016/06/20/eu-dont-send-syrians-back-turkey>. Acesso em: 3 ago. 2020. 
novos infectados pela Covid-19, além de o vírus começar a atingir outros países europeus. Como consequência, diversos desses países fecharam suas fronteiras externas e voltaram a controlar as fronteiras internas. Embora o Espaço Schengen preveja que a circulação de pessoas deve ser livre, há exceçóes regulamentadas pelo tratado. É possível, portanto, que os países controlem ou mesmo fechem as suas fronteiras internas em situaçóes excepcionais, como a da pandemia (European Commission, 2020c). Com relação às fronteiras externas, a decisão também é individual de cada Estado-membro, sempre observando as recomendaçôes das instituiçôes europeias. E, assim como houve a recomendação de restriçôes temporárias em março, a recomendação, desde junho, é de uma abertura gradual, com uma seleção de nacionais de países com a entrada permitida (European Commission, 2020a).

Percebe-se, portanto, que a União Europeia vem gerenciando atualmente duas graves crises: ${ }^{9}$ a migratória e a sanitária.

Conforme o Estatuto do Refugiado Europeu, ${ }^{10}$ todos os refugiados e outros migrantes forçados elegíveis para a proteção subsidiária têm direito à saúde. Ademais, têm direito a auxílio para a sua subsistência, como alojamento, alimentaçáo e cuidados básicos e higiene. ${ }^{11} \mathrm{Ou}$ seja, os que estáo devidamente instalados e residindo em países europeus têm, em tese, seus direitos garantidos, inclusive eventuais auxílios financeiros emergenciais.

Em contrapartida, os solicitantes que ainda não tiveram seus processos de refúgio concluídos não têm essa garantia. Cada país pode adotar seus próprios critérios de gerenciamento, a partir das regras estabelecidas pelo Sistema Europeu de Asilo, tendo por base o respeito à proteçáo dos direitos humanos. Alguns países concedem auxílio financeiro (não necessariamente um programa de auxílio emergencial) aos solicitantes. A Alemanha, a Áustria e a Dinamarca, por exemplo, concedem dinheiro em espécie aos solicitantes diretamente nos alojamentos (European Commission, 2020b).

Considerando a legislação europeia e os demais tratados internacionais, alguns direitos básicos foram restritos pelos países europeus em razão da pandemia. De qualquer forma, a Comissão Europeia estabeleceu orientaçôes para os Estados-membros, nas quais observa que todas as solicitaçôes de asilo devem ser registradas (mesmo com atraso) e todos os solicitantes devem ter pleno acesso à saúde (European Commission, 2020b). Ou seja, na teoria, todos os direitos estão garantidos, a questão é a sua aplicação pelos Estados-membros no dia a dia.

No que concerne ao patrulhamento de rotas marítimas, é lícita a fiscalização de contrabando de migrantes e de tráfico de pessoas, mas ilícita a devolução daqueles migrantes forçados que estavam realmente fugindo de seu país de origem e, durante o percurso migratório, foram vítimas de contrabandistas ou traficantes. Muitos dos migrantes contrabandeados são refugiados, uma vez que a condição de refugiado é declarativa e não constitutiva. Não poderiam, portanto, ser devolvidos, conforme o princípio do non-refoulement, garantido por tratados internacionais e pelo Estatuto do Refugiado Europeu. Nem mesmo uma pandemia pode se sobrepor a esse direito. Deveria ser garantido o direito de acesso, mas respeitando-se o período de quarentena.

Ressalte-se, por fim, que há migrantes que têm conseguido chegar à fronteira de algum país europeu durante este período de pandemia. Nesses casos, os países têm adotado procedimentos

9. Entre outras, como o Brexit.

10. Disponível em: <https://eur-lex.europa.eu/legal-content/PT/TXT/PDF/?uri=CELEX:32011L0095\&from=PT>. Acesso em: 19 jul. 2020.

11. Disponível em: <https://eur-lex.europa.eu/legal-content/PT/TXT/PDF/?uri=CELEX:32013L0033\&from=PT>. Acesso em: 19 jul. 2020. 
domésticos, destacando-se a obrigatoriedade de cumprimento da quarentena. Tal período vem sendo cumprido em locais previamente destinados pelos países. Alguns, como a Irlanda, têm realizado testes de Covid-19 nos novos solicitantes na chegada, enquanto outros, como a Itália, têm aplicado os testes após o período de quarentena (EASO, 2020).

Além dessas questôes jurídicas e institucionais, a pandemia e a crise migratória também refletem em questôes políticas e econômicas, como será visto a seguir.

\subsection{Aspectos políticos e econômicos}

Antes de a Itália tornar-se o epicentro da pandemia da Covid-19, em março de 2020, a União Europeia ainda se reestruturava após a saída do Reino Unido do bloco em 31 de janeiro, buscando novas agendas políticas e fontes de reorganização financeira e orçamentária, dado o vácuo deixado pela saída dos aportes de Londres para Bruxelas.

O contexto político e econômico apontava para uma projeção hegemônica de Alemanha e França, que deveriam buscar a coesão interna do bloco e promover as esperadas reformas institucionais, tão aguardadas desde o anúncio do Brexit em 2016. Na esteira, Bruxelas deparava-se com as pressóes para um maior controle migratório, sobretudo nas bordas do bloco, como Itália, Grécia, Bulgária e Romênia, e nas tensôes geopolíticas e fronteiriças com a Turquia e a Rússia, além da reabertura dos processos de admissão de novos membros dos Bálcãs.

No âmbito político, países como Hungria e Polônia acenavam para um exacerbamento de suas agendas nacionalistas e de extrema direita; enquanto isso, Portugal e os países nórdicos, à exceção da Suécia, apontavam para uma agenda social-democrata. No plano das relaçóes externas, planteava-se a votação do acordo de livre comércio com o Mercosul, a aproximação com a China, conforme afirma Prins (2018), e um distanciamento, o qual chamaremos de autonomia protagonista, dos Estados Unidos sob a administraçáo de Donald Trump, de acordo com as impressóes de Gardner (2020).

Com relação às questóes migratórias pré-pandemia, cabe ressaltar a guinada tomada pela Espanha com a inauguração do governo socialista em junho de 2018, seguida pela Alemanha, por países do Benelux e pela Dinamarca, no sentido de receber e acolher solicitantes de refúgio e tentar instituir uma agenda para a regularização de imigrantes indocumentados. Portugal, posteriormente, também se soma a esse grupo e terá um papel fundamental já no contexto da pandemia.

Após a declaração da pandemia, as primeiras respostas políticas do bloco europeu foram no sentido de controle e fechamento de suas fronteiras externas, salvo alguns exemplos internos, como Portugal e Espanha, e da proibição, mais tarde, por países do bloco, de voos e admissão de pessoas que haviam visitado países com surtos epidemiológicos, como Brasil e Estados Unidos. O movimento de indivíduos extrabloco que já se encontravam dentro do Espaço Schengen foi permitido com limitaçóes, respeitando cada controle fronteiriço nacional.

Ao contrário do Mercosul, conforme veremos na próxima seção, a União Europeia, sob a liderança de Angela Merkel, primeira-ministra alemã, institucionalizou uma agenda de coesão e colaboraçáo política para o combate aos efeitos da pandemia e promoveu a criação de um pacote de $€ 750$ bilhóes (Pinto, 2020) para mitigar os impactos econômicos e evitar uma nova crise como a da Zona do Euro de 2012, ou pior. 
Entre os aspectos que concernem à agenda migratória durante a pandemia da Covid-19 na União Europeia, alguns exemplos nacionais merecem destaque, como Portugal, Itália, França e Hungria, que adotaram mecanismos diferentes. Enquanto Portugal ${ }^{12}$ e Franç ${ }^{13}$ implementaram, respectivamente, políticas de regularização de imigrantes - para permitir o acesso aos serviços de saúde - e modelos de distanciamento social por bandeiras, Itália e Hungria ${ }^{14}$ vislumbraram uma agenda mais punitiva a imigrantes e estrangeiros, com expulsôes, deportaçôes e suspensão de autorizaçôes de residência, respectivamente.

Ademais, a Comissão Europeia declarou, em seu documento A Hora da Europa: reparar os danos e preparar o futuro para a próxima geração (Comissão Europeia, 2020), o seguinte com relação às migraçóes no pós-pandemia.

A crise também colocou os sistemas de asilo dos Estados-membros e a gestão das fronteiras da União Europeia sob enorme pressão. Como o novo pacto em matéria de migração e asilo procurar-se-á tornar a gestão dos sistemas de asilo, da migração e das fronteiras da EU [União Europeia] mais eficaz, mais justa e suficientemente flexível para responder a situaçôes de crises.

A referida declaração encontra ressonância nos aspectos mencionados, sobretudo aqueles levados a cabo por países da Europa Ocidental e da Escandinávia, ao passo que os Estados do Leste Europeu, do Mediterrâneo e os eslavos adotam uma postura mais reticente e até mesmo restritiva com relação às migraçóes no pós-pandemia, especialmente considerando a origem dessas migraçóes, Norte da África e Oriente Médio, regiôes que poderiam representar novas ondas da Covid-19, segundo Sumner, Hoy e Ortiz-Juarez (2020) e Arezki e Nguyen (2020).

Isto posto, as respostas políticas e econômicas da União Europeia à pandemia sinalizam que levarão em consideração os aspectos centrais das políticas de asilo humanitário, porém ainda reproduzirão, em certa medida, cenários do contexto prévio à pandemia, como de restriçóes, náo regularizaçóes e manutenção de abrigos e campos de refugiados, a exemplo de Itália e França.

Ainda, o aumento do controle fronteiriço nas fronteiras europeias, a fim de evitar o ingresso de pessoas oriundas de países com elevados graus de contágio, poderá somar-se a uma agenda velada de maiores restriçóes às migraçóes, em que pese a maior demanda por mão de obra nos países mais afetados pela crise pandêmica, conforme apontado pelo relatório de reconstrução desse bloco. Nessa mesma direção, veremos na próxima seção os aspectos e as conjunturas para o caso do Mercosul.

\section{O CONTEXTO DO MERCOSUL}

\subsection{Aspectos jurídicos e institucionais}

Assim como a União Europeia, o Mercosul também possui regulamentações sobre a questão migratória, porém em menor quantidade. Sendo um bloco que inclui a livre circulação de pessoas, há regulamentos

\footnotetext{
12. Disponível em: <https://eco.sapo.pt/2020/03/28/sef-vai-legalizar-todos-os-estrangeiros-em-situacao-irregular-em-portugal/> . Acesso em: 29 jul. de 2020.

13. Disponível em: <https://www.leparisien.fr/societe/coronavirus-votre-departement-est-il-en-vert-orange-ou-rouge-voici-la-carte-de-francedu-deconfinement-30-04-2020-8308836.php>. Acesso em: 29 jul. de 2020.

14. Disponível em: <https://www.france24.com/en/20200313-hungary-s-pm-orban-blames-foreign-students-migration-for-coronavirusspread>. Acesso em: 29 jul. 2020.
} 
específicos sobre questôes trabalhistas, previdenciárias, reconhecimento de diplomas, turismo, direitos civis, facilitação de residência, entre outros. No entanto, o fato de ter objetivos e estrutura institucional muito diferentes da Uniáo Europeia faz com que as regulamentaçóes internas sejam bem menos específicas e em menor número. ${ }^{15}$

A regulamentação migratória teve início de fato em 2002, com o estabelecimento de acordos para regulamentar a questão dos imigrantes entre os países do bloco e também com os países associados (Chile e Bolívia). No ano seguinte, 2003, foi criado o Foro Especializado Migratório, com o objetivo de analisar o impacto das migrações no bloco.

Em 2004, logo após o estabelecimento do foro citado, foram elaborados os Princípios Migratórios, tendo por base a proteção dos direitos humanos e a regularização de todos os migrantes do bloco. Tais princípios são aplicáveis a todos os migrantes, incluindo os nacionais de terceiros países. Nesse documento, os países se comprometem a cumprir as regulamentaçóes internacionais e regionais específicas para refugiados e, também, a prevenir e combater o tráfico de pessoas (Mercosur, 2004).

Em 2012, foi elaborado outro documento, dessa vez tratando especificamente dos refugiados, sem envolver a questão do tráfico de pessoas e outros tipos de migrantes. A Declaração de Princípios do Mercosul sobre a Proteção Internacional dos Refugiados ressalta o princípio básico do direito internacional dos refugiados, que é o non-refoulement, além da garantia dos mesmos direitos concedidos aos estrangeiros residentes nos países do Mercosul, bem como outros direitos previstos em instrumentos internacionais e regionais.

Com exceção dos acordos firmados para regulamentar a circulação de pessoas no Mercosul, os demais instrumentos citados são classificados como soft law. Ou seja, todos os documentos que abordam a questão dos refugiados no bloco são orientaçôes para os Estados-membros, não sendo considerados tratados regionais. Não obstante, esses documentos enfatizam que os Estados-membros devem seguir os tratados e os demais documentos internacionais e regionais. Inclusive, todos os membros do bloco são signatários da Convenção sobre Refugiados de 1951 e de seu Protocolo de 1967, além de serem signatários da grande maioria de tratados sobre direitos humanos em âmbito internacional e regional. É possível afirmar, portanto, que esses países estão vinculados às principais regulamentaçóes sobre o direito dos migrantes.

Conforme já explanado nas seçôes anteriores, vivemos atualmente um período de grave crise sanitária, que afeta os direitos mais básicos dos migrantes devido à sua condição de vulnerabilidade. E, até este momento (4 de agosto de 2020), não há qualquer documento no Mercosul abordando a questão dos imigrantes e da pandemia. De qualquer forma, é importante ressaltar que os documentos existentes no bloco deixam claro que todos os migrantes (nacionais do bloco ou de terceiros países) têm direito à saúde - a Declaração de Santiago, de 2004, já previa que os países deveriam organizar um regime comum de saúde, que tomou formas mais concretas no final de 2019, mas ainda não foi consolidado.

15. Ressalte-se que é difícil comparar as legislações do Mercosul com as da União Europeia, uma vez que se trata de sistemas jurídicos distintos. Enquanto no bloco sul-americano a legislação é formada por tratados regionais, no bloco europeu ela é formada, principalmente, pelo direito comunitário, além de alguns tratados. No Mercosul, os tratados existentes abordam diversas temáticas (questões trabalhistas, previdenciárias, migratórias etc.) de forma mais abrangente. Em contrapartida, na União Europeia, existe um processo legislativo no âmbito das instituições europeias, criando, assim, diversas leis comunitárias e que são supranacionais. Em razão disso, as regulamentações são muito mais detalhadas, pois se trata de um novo sistema jurídico. 
A partir de interpretação dos princípios citados anteriormente (de 2004 e 2012), entendemos que os direitos sociais também devem ser estendidos aos imigrantes. Portanto, os benefícios sociais concedidos pelos governos, como o auxílio emergencial, também devem ser garantidos aos imigrantes.

É importante ressaltar que os documentos não fazem menção àqueles imigrantes que não estão devidamente regularizados. Observamos, todavia, que é muito difícil que os imigrantes irregulares tenham acesso a eventuais benefícios sociais, uma vez que a sua presença no país não é, supostamente, de conhecimento do governo. Isso quer dizer que é preciso estar cadastrado no país - ter Cadastro de Pessoas Físicas (CPF) se estiver no Brasil, por exemplo - para poder receber qualquer auxílio.

No caso do direito à saúde, o imigrante irregular também encontrará dificuldade. Mas provavelmente receberá atendimento, uma vez que todos os documentos do Mercosul relativo aos migrantes enfatizam a proteção dos direitos humanos.

Ressalte-se, ainda, que todos os Estados-membros do Mercosul fazem parte do Sistema Interamericano de Proteção dos Direitos Humanos e a regulamentação da Comissão Interamericana de Direitos Humanos é muito clara: todos os imigrantes, sem qualquer discriminação, têm direito à saúde pública. Ademais, a comissão enfatiza que não deve haver qualquer medida que desencoraje o acesso do imigrante ao sistema de saúde, como o controle de imigrantes ou o compartilhamento de informaçóes com o governo. Os dados devem ser sigilosos (IACHR, 2020).

Como se pode perceber, em tese, todos os imigrantes teriam direito à proteçáo durante a pandemia. A questáo que se coloca é sobre o período pós-pandemia. Por isso, o ideal seria a regularizaçáo de todos os migrantes irregulares, a fim de garantir um amplo acesso à saúde e aos benefícios sociais, como Portugal o fizera, conforme apresentamos na seção anterior. Nesse aspecto, veremos na próxima subseção as respostas políticas e econômicas por parte dos países do bloco mercosulino.

\subsection{Aspectos políticos e econômicos}

A situação política do Mercosul no começo de 2020, portanto, prévia à declaração da pandemia da Covid-19, apontava para um processo de transformaçôes, com a inauguração de um novo governo de centro-esquerda na Argentina e um de centro-direita no Uruguai, uma ameaça de impeachment no Paraguai e a manutenção das turbulências políticas no Brasil, cada vez mais afastado do bloco desde a posse do novo governo, cuja chancelaria tem priorizado agendas bilaterais e de realinhamento total aos Estados Unidos.

No âmbito econômico e político, cada país do bloco segue uma direção diferente: a Argentina busca ocupar o protagonismo deixado pelo Brasil, enquanto este se distancia; o Paraguai se isola, em virtude das suas crises internas e das dificuldades de negociação com a China, principal parceira do bloco, pois reconhece apenas Taiwan; e o Uruguai pauta-se pela autonomia no bloco, evitando subjugar-se a uma relação de dependência total aos demais membros.

Como cada país adotou uma política própria, ao contrário da União Europeia, de mitigação dos efeitos da pandemia nas searas econômicas - com reflexos nas migraçóes e no mercado de trabalho -, apresentamos o quadro 1 com a síntese de cada Estado-membro do Mercosul. 


\section{QUADRO 1}

Respostas dos países do Mercosul à pandemia da Covid-19 e questões migratórias e fronteiriças

\begin{tabular}{|c|c|c|c|c|}
\hline Pais/tópico & Contexto das políticas migratórias & Questões fronteiriças & Cenário da Covid-19 e seus impactos & Política externa \\
\hline Argentina & $\begin{array}{l}\text { Nova Lei de Migração em 2004; } \\
\text { decreto necessário e urgente } \\
\text { de 2017; política migratória de } \\
\text { Alberto Fernández. }\end{array}$ & $\begin{array}{l}\text { Fechamento de todas as fronteiras } \\
\text { em } 27 \text { de março; reabertura gradual, } \\
\text { planificada e segura em } 10 \text { de abril; } \\
\text { abertura para estrangeiros em } \\
\text { 1ํ de setembro. }\end{array}$ & $\begin{array}{l}\text { Quarentena geral; interrupção dos } \\
\text { fluxos imigratórios; queda no turismo; } \\
\text { manifestações contra o lockdown. }\end{array}$ & $\begin{array}{l}\text { Nova postura regional e internacional } \\
\text { após a posse de Fernández; retomada } \\
\text { do diálogo com a Venezuela; ocupação } \\
\text { da lacuna deixada pelo Brasil. }\end{array}$ \\
\hline Brasil & $\begin{array}{l}\text { Nova Lei de Migração em 2017; } \\
\text { Portaria no 666/2019; política } \\
\text { migratória de Jair Bolsonaro. }\end{array}$ & $\begin{array}{l}\text { Fechamento de fronteiras terrestres em } \\
19 \text { de março; repatriação de brasileiros; } \\
\text { portos e aeroportos abertos. }\end{array}$ & $\begin{array}{l}\text { Distanciamento social estadualizado; } \\
\text { fluxos de venezuelanos mantidos; } \\
\text { reabertura no meio da pandemia; } \\
\text { auxílio emergencial para imigrantes. }\end{array}$ & $\begin{array}{l}\text { Revisão da política externa brasileira; } \\
\text { isolamento internacional agravado; } \\
\text { questões do PROSUL e Grupo de Lima; } \\
\text { afastamento do Mercosul. }\end{array}$ \\
\hline Paraguai & $\begin{array}{l}\text { Lei de 1996; acordo com o } \\
\text { Mercosul; política migratória de } \\
\text { Mario Abdo Benítez. }\end{array}$ & $\begin{array}{l}\text { Fechamento de fronteiras terrestres } \\
\text { em } 24 \text { de março; Ponte da Amizade } \\
\text { e barreiras sanitárias com o Brasil; } \\
\text { trânsito de mercadorias autorizado. }\end{array}$ & $\begin{array}{l}\text { Política de isolamento social; crise } \\
\text { institucional e política; repatriação } \\
\text { de brasileiros e argentinos; } \\
\text { fluxos de turistas e comércio } \\
\text { binacional impactados. }\end{array}$ & $\begin{array}{l}\text { Isolamento no Mercosul; } \\
\text { reconhecimento de Taiwan; dificuldades } \\
\text { com a China. }\end{array}$ \\
\hline
\end{tabular}

Elaboração dos autores.

Obs.: PROSUL - Foro para o Progresso e Integração da América do Sul.

De acordo com o quadro anterior, é possível identificar, portanto, diferentes agendas e mecanismos adotados por Buenos Aires, Brasília, Assunção e Montevidéu, desde o lockdown na Argentina até a estadualização das medidas de distanciamento social no Brasil. O impacto sobre a mobilidade humana intrabloco foi observado, uma vez que o único ponto em comum entre os quatro Estados foi o fechamento de fronteiras.

Os impactos da Covid-19 em migrantes no Mercosul foram abordados, de maneira política e institucional, apenas em um seminário realizado pelo Instituto de Políticas Públicas em Direitos Humanos (IPPDH) do Mercosul no começo de julho de 2020, intitulado Conversatorio Virtual sobre Gobernanza Migratoria y Pandemia de Covid-19, que contou com a colaboraçáo do escritório regional da Organização Internacional para as Migraçóes (OIM).

Em que pesem essas questôes, o fluxo de venezuelanos e haitianos, cujo caráter crítico pré-pandemia apontamos na introdução deste texto, manteve-se durante o período, de acordo com o último relatório mensal do Observatório das Migrações Internacionais (OBMigra) (Cavalcanti et al., 2020), e os migrantes sofreram impactos diretos, sobretudo no acesso aos serviços básicos de saúde, abrigo, auxílio financeiro ${ }^{16} \mathrm{e}$ moradia, cujas respostas, conforme pontuamos, foram diferentes em cada um dos países do bloco.

\section{CONSIDERAÇÕES FINAIS}

Há um século, o SI começava a se recuperar dos efeitos da Gripe de 1918, que não apenas alterou a ordem mundial no ínterim da Primeira Guerra Mundial, mas também teve consequências para os concertos regionais na Europa, nas Américas e no Oriente Médio, principalmente, e, por conseguinte, afetou a mobilidade humana internacional, sobretudo os fluxos migratórios de refugiados da guerra.

16. São vários os relatos das dificuldades de imigrantes e refugiados em receber o auxílio emergencial do governo brasileiro, os quais têm direito. Mais informações disponíveis em: <https://www.folhape.com.br/economia/caixa-barra-pagamento-de-ajuda-de-r-600-a-imigrantes/139689/> e <https://g1.globo.com/economia/noticia/2020/05/28/imigrantes-enfrentam-dificuldades-para-acessar-o-auxilio-emergencial-em-sp.ghtml>. 
Um século depois, deparamo-nos com uma nova pandemia, cujos reflexos na economia, na política e nas relaçôes internacionais já se apresentam em patamares superiores àqueles verificados em crises sanitárias globais anteriores. Nesse contexto, as migraçóes não deixariam de sofrer os efeitos da Covid-19, uma vez que fronteiras foram fechadas e fluxos foram interrompidos quase que na sua totalidade, o que procuramos analisar na segunda seçáo, com foco na União Europeia e no Mercosul, dois blocos que estâo inseridos nas regióes com os maiores indicadores de contaminados e óbitos pelo novo coronavírus.

No âmbito da União Europeia, foi possível observar uma governança de coesão, que buscou mitigar os impactos econômicos - e geopolíticos - da pandemia, cujos reflexos se observaram também nas migraçôes, apesar do fechamento de fronteiras e da proibição de admissão de estrangeiros extranacionais do bloco, que contam com um item específico no plano de recuperação proposto pela Comissão Europeia, conforme abordado na terceira seção.

Dessa maneira, as perspectivas advindas de tal conjuntura sinalizam para um agravamento das tensôes sociais internas e dos sentimentos anti-imigração, como em Hungria, Polônia e Itália, representados, sobretudo, na xenofobia social e institucional. Exemplos positivos, como de Portugal e Dinamarca, que criaram mecanismos de regularização e assistência a imigrantes e solicitantes de refúgio, coordenam-se com a agenda de recuperação proposta por Alemanha e França para o pós-pandemia, países estes que assumiram na sua totalidade a liderança do bloco após a saída do Reino Unido meses antes da pandemia.

Com relaçáo ao Mercosul, bloco que passa por um shift de identidade - e legitimidade - desde 2019, verificou-se na quarta seção um panorama distinto àquele da Uniāo Europeia, com a adoção de medidas de mitigação dos efeitos da pandemia da Covid-19 de maneira autônoma, independente e, praticamente, sem coordenação com os demais países do bloco. A assunção de novos governos na Argentina e no Uruguai, somada às instabilidades políticas de Paraguai e Brasil, serviu de plano de fundo para a pandemia e para as próprias migraçôes em curso no bloco, como de venezuelanos e haitianos.

Como cada país mercosulino adotou uma resposta diferenciada à pandemia, os reflexos nas migraçôes também foram distintos em cada país. É do nosso entendimento que, considerando as políticas externas de Buenos Aires, Brasília, Assunção e Montevidéu, a questão migratória se diluiu nas discussões do Mercosul, salvo questóes pontuais, como o fechamento de fronteiras e açóes inéditas, como o caso dos acordos firmados entre o governador do Rio Grande do Sul e o presidente do Uruguai, no sentido de permitir a livre circulação de pessoas entre a Unidade Federativa (UF) brasileira e o país vizinho (Egídio, 2020). Verifica-se, em síntese, uma espécie de novo regionalismo no seio do bloco, o que merecerá um aprofundamento em discussóes e pesquisas futuras.

Em suma, a partir desta análise conjuntural dos efeitos da pandemia da Covid-19 nas migraçôes internacionais para a União Europeia e o Mercosul, foi possível inferir diferentes respostas nos níveis comunitários, nacionais e subnacionais, bem como a adoção e a implementação de diferentes mecanismos jurídicos e institucionais, que apontam, segundo a nossa conclusão, para diferentes estágios de institucionalização nos dois blocos. Dessa maneira, verifica-se que tais efeitos serão percebidos de forma mais coesa e no entorno de uma linearidade na Uniáo Europeia, enquanto no Mercosul serão sensivelmente diferentes em cada um dos países do bloco. Consideraçóes mais amplas sobre os impactos da pandemia na mobilidade internacional serão possíveis somente com o seu término, que se dará, conforme observado, em diferentes épocas em cada região e país. 


\section{REFERÊNCIAS}

AREZKI, R.; NGUYEN, H. Novel coronavirus hurts the Middle East and North Africa through many channels. In: BALDWIN, R.; DI MAURO, B. W. Economics in the Time of Covid-19. London: CEPR Press, 2020. p. 53-58.

CAVALCANTI, L. et al. Acompanhamento de fluxo e empregabilidade dos imigrantes no Brasil: relatório mensal do OBMigra. Brasília: OBMigra, 2020. Disponível em: <https://portaldeimigracao.mj.gov.br/images/ relatorios_mensais/2020/OBMigra_Abril_2020.pdf>. Acesso em: 29 jul. 2020.

CHOUDHARI, R. Covid-19 pandemic: mental health challenges of internal migrant workers of India. Asian Journal of Psychiatry, v. 54, p. 1-4, Dec. 2020. Disponível em: <https://doi.org/10.1016/j.ajp.2020.102254>. Acesso em: 14 jul. 2020.

COMISSÃO EUROPEIA. A hora da Europa: reparar os danos e preparar o futuro para a próxima geração. Bruxelas: Comissão Europeia, 27 maio 2020. Disponível em: <https://eur-lex.europa.eu/legal-content/PT/ TXT/HTML/?uri=CELEX:52020DC0456\&from=PT>. Acesso em: 15 jul. 2020.

EASO - EUROPEAN ASYLUM SUPPORT OFFICE. Covid-19 emergency measures in asylum and receptions systems. [s.1]: EASO, 2 jun. 2020. Disponível em: <https:/www.easo.europa.eu/sites/default/ files/covid19-emergency-measures-asylum-reception-systems.pdf>. Acesso em: 20 jul. 2020.

EGÍDIO, P. Como será o acordo entre Rio Grande do Sul e Uruguai para a prevenção do coronavírus na fronteira. GaúchaZH, 2020. Disponível em: <https:/gauchazh.clicrbs.com.br/colunistas/rosane-de-oliveira/ noticia/2020/06/como-sera-o-acordo-entre-rio-grande-do-sul-e-uruguai-para-a-prevencao-do-coronavirusna-fronteira-ckb2qcclo003j015n1czsz59t.html>. Acesso em: 29 jul. 2020.

EUROPEAN COMMISSION. Coronavirus: commission recommends partial and gradual lifting of travel restrictions to the EU after 30 June based on common coordinated approach. Brussels: European Comission, 11 June 2020 a. Disponível em: <https://ec.europa.eu/commission/presscorner/detail/en/ip_20_1035>. Acesso em: 3 ago. 2020.

Covid-19: guidance on the implementation of relevant EU provisions in the area of asylum and return procedures and on resettlement. Brussels: European Comission, 16 Apr. 2020b. Disponível em: <https://bit. ly/3eRlud0>. Acesso em: 20 jul. 2020.

Temporary reintroduction of border control. Brussels: European Comission, 2020c. Disponível em: <https://ec.europa.eu/home-affairs/what-we-do/policies/borders-and-visas/schengen/reintroductionborder-control_en>. Acesso em: 3 ago. 2020.

GARDNER, A. L. Stars with stripes: the essential partnership between the European Union and the United States. New York: Palgrave Macmillan, 2020.

GIL, A. C. Métodos e técnicas de pesquisa social. 7. ed. São Paulo: Atlas, 2019.

IACHR - INTER-AMERICAN COMMISSION ON HUMAN RIGHTS. Pandemic and human rights in the Americas. Washington: IACHR, 10 Apr. 2020. Disponível em: <https://www.oas.org/en/iachr/decisions/ pdf/Resolution-1-20-en.pdf>. Acesso em: 1 jul. 2020.

MADURO ordena reforzar frontera con Brasil por la pandemia. CNN en Español, 2020. Disponível em: $<$ https:/cnnespanol.cnn.com/2020/04/22/alerta-venezuela-maduro-ordena-reforzar-frontera-con-brasil-porla-pandemia-coronavirus/>. Acesso em: 14 jul. 2020.

MANTOVANI, F. Crianças venezuelanas imigrantes dormem com fome durante pandemia, diz estudo. Folha de S.Paulo, 18 jun. 2020. Disponível em: <https:/www1.folha.uol.com.br/mundo/2020/06/criancasvenezuelanas-imigrantes-dormem-com-fome-durante-pandemia-diz-estudo.shtml>. Acesso em: 29 jul. 2020.

MASSEY, D. S. Comprender las migraciones internacionales: teorías, prácticas y políticas migratorias. Barcelona: Edicions Bellaterra, 2017. 
MELILLA border fence stormed by 260 migrants, 53 pass over. ANSAmed, 2020. Disponível em: <https:// bit.ly/3hsDo7k>. Acesso em: 14 jul. 2020.

MERCOSUR - MERCADO COMÚN DEL SUR. Declaración de Santiago sobre principios migratorios. [s.l.]: ACNUR, 17 maio 2004. Disponível em: <http://old.acnur.org/fileadmin/Documentos/BDL/2013/9083. pdf>. Acesso em: 1 jul. 2020.

PADUAN, R. Bolsonaro anuncia fechamento de fronteira com a Venezuela. Veja, 2020. Disponível em: $<$ https://veja.abril.com.br/politica/bolsonaro-anuncia-fechamento-de-fronteira-com-a-venezuela/>. Acesso em: 14 jul. 2020.

PINTO, A. E. de S. União Europeia lança pacote de 750 bilhôes de euros para reconstruir bloco após coronavírus. GaúchaZH, 2020. Disponível em: <https://bit.ly/2CGB65P>. Acesso em: 15 jul. 2020.

PRINS, N. Collusion: how central bankers rigged the world. New York: Bold Type Books, 2018.

ROTHMAN, S.; GUNTURU, S.; KORENIS, P. The mental health impact of the COVID-19 epidemic on immigrants and racial and ethnic minorities. QJM: an International Journal of Medicine, n. 203, p. 1-5, June 2020. Disponível em: <https://doi.org/10.1093/qjmed/hcaa203>. Acesso em: 14 jul. 2020.

RUYT, J. The EU-Turkey summit of 29 November 2015: a "re-energized" relationship. Global Policy Watch, 1 Dec. 2015. Disponível em: <https://www.globalpolicywatch.com/2015/12/the-eu-turkey-summit-of-29november-2015-a-re-energised-relationship/>. Acesso em: 3 ago. 2020.

SANTOS, M. A natureza do espaço: técnica e tempo, razão e emoção. 4. ed. São Paulo: Edusp, 2006.

SAYAD, A. A imigração: ou os paradoxos da alteridade. 1. ed. São Paulo: Edusp, 1998.

SUMNER, A.; HOY, C.; ORTIZ-JUAREZ, E. Estimates of the impact of Covid-19 on global poverty. [s.l.]: WIDER, Apr. 2020. p. 1-14. (Working Paper, n. 2020/43). Disponível em: <https://bit.ly/3fVkXYH>. Acesso em: 15 jul. 2020.

UEBEL, R. R. G. Política externa migratória brasileira: das migrações de perspectiva à hiperdinamização das migraçóes durante os governos Lula da Silva e Dilma Rousseff. 2018. 645 f. Tese (Doutorado) - Programa de Pós-Graduação em Estudos Estratégicos Internacionais, Universidade Federal do Rio Grande do Sul, Porto Alegre, 2018. Disponível em: <https://lume.ufrgs.br/handle/10183/188410>. Acesso em: 14 jul. 2020.

URAS, U. Turkey, EU and the imperilled refugee deal. Al Jazeera, 3 Mar. 2020. Disponível em: <https:// www.aljazeera.com/news/2020/03/turkey-eu-imperilled-refugee-deal-200302085719576.html>. Acesso em: 3 ago. 2020.

\section{BIBLIOGRAFIA COMPLEMENTAR}

CORTE INTERAMERICANA DE DIREITOS HUMANOS. Advisory opinion OC-25/18. [s.l.]: [s.n.], 30 maio 2018. Disponível em: <https://www.refworld.org/cases,IACRTHR,5c87ec454.html>. Acesso em: 20 maio 2020.

IDMC - INTERNAL DISPLACEMENT MONITORING CENTER. Global internal displacement database. [s.l.]: IDMC, [s.d.]. Disponível em: <https://www.internal-displacement.org/database>. Acesso em: 1 jul. 2020.

MERCOSUL. Declaraçáo de princípios do Mercosul sobre proteçáo internacional de refugiados. [s.l.]: Mercosul, 23 nov. 2012. Disponível em: <http://www.migraciones.gov.ar/conare/pdf/fortaleza\%202012. pdf>. Acesso em: 1 jul. 2020.

Acordo sobre residência para nacionais dos Estados-partes do Mercosul. [s.l.]: Mercosul, 6 dez. 2020. Disponível em: <https://www.mercosur.int/pt-br/cidadaos/residir/>. Acesso em: 1 jul. 2020. 
